\title{
Inflammation, plasticity and real-time imaging after cerebral ischemia
}

\author{
Jasna Kriz • Mélanie Lalancette-Hébert
}

Received: 12 November 2008 / Revised: 5 February 2009 / Accepted: 6 February 2009 / Published online: 19 February 2009

(C) The Author(s) 2009. This article is published with open access at Springerlink.com

\begin{abstract}
With an incidence of approximately 350 in 100,000 , stroke is the third leading cause of death and a major cause of disability in industrialized countries. At present, although progress has been made in understanding the molecular pathways that lead to ischemic cell death, the current clinical treatments remain poorly effective. There is mounting evidence that inflammation plays an important role in cerebral ischemia. Experimentally and clinically, brain response to ischemic injury is associated with an acute and prolonged inflammatory process characterized by the activation of resident glial cells, production of inflammatory cytokines as well as leukocyte and monocyte infiltration in the brain, events that may contribute to ischemic brain injury and affect brain recovery and plasticity. However, whether the post-ischemic inflammatory response is deleterious or beneficial to brain recovery is presently a matter of debate and controversies. Here, we summarize the current knowledge on the molecular mechanisms underlying post-ischemic neuronal plasticity and the potential role of inflammation in regenerative processes and functional recovery after stroke. Furthermore, because of the dynamic nature of the brain inflammatory response, we highlight the importance of the development of novel experimental approaches such as real-time imaging. Finally, we discuss the novel transgenic reporter mice models that have allowed us to visualize and to analyze the processes such as
\end{abstract}

J. Kriz $(\bowtie) \cdot$ M. Lalancette-Hébert Department of Anatomy and Physiology,

Faculty of Medicine, Centre de Recherche

du Centre Hospitalier de l'Université Laval (CHUQ),

T3-67, Laval University, 2705 Boulevard Laurier,

Quebec, QC G1V 4G2, Canada

e-mail: Jasna.Kriz@crchul.ulaval.ca neuroinflammation and neuronal repair from the ischemic brains of live animals.

Keywords Stroke $\cdot$ Neuroinflammation $\cdot$ Microglia . Brain recovery $\cdot$ Biophotonic/bioluminescence imaging · Transgenic reporter mouse models

\section{Introduction}

After heart disease and cancer, with an incidence of approximately 350 in 100,000 , stroke is the third leading cause of death and a major cause of disability in industrialized countries [34, 87]. In the last decade, according to the American Heart Association, the mortality rate from stroke has declined by approximately $12 \%$; however, the total number of stroke cases is not in decline and may actually be rising [118]. Moreover, stroke represents a major social burden for society. In fact, only a minority of stroke patients will completely recover and, in most instances, ischemic brain injuries are associated with mild to severe permanent neurological deficits. These deficits can include partial paralysis, difficulties with memory, thinking, language and movements. In practice, the term "stroke" refers to an umbrella of conditions caused by the occlusion or hemorrhage of blood vessel supplying the brain [8, 34, 87]. In all instances, stroke ultimately involves dysfunction and death of brain cells and neurological deficits that reflect the location and size of the compromised brain area. At present, although progress has been made in understanding the molecular pathways that lead to ischemic cell death, the current clinical treatments remain poorly effective [34, 87]. The only approved therapy is thrombolysis induced by intravenous administration of recombinant tissue plasminogen activator (tPA); however, because of a short therapeutic 
time window, only a small fraction of patients can benefit from this treatment. According to a current view, treatment of stroke is suboptimal without a combination of clot-lysing therapy with neuroprotection and/or pro-regeneration treatments [45, 46, 87]. Therefore, the quest for novel and more effective therapeutic strategies remains a priority. An additional problem, in designing effective therapeutic strategies for stroke, may lay in the fact that most targets, such as inflammation, may have a dual and possibly time-dependent role (Janus effect) in the complex pathological cascade of events associated with the brain response to ischemic injury [39, 45, 75].

In this review, we give a short overview of the pathophysiological events involved in the evolution of ischemic brain damage, and the potential role of inflammation in regenerative processes and functional recovery after stroke. Furthermore, because of the dynamic and very complex nature of the brain inflammatory response, we will highlight the importance for development of novel experimental approaches to study neuroinflammation, such as real-time imaging. Finally, we will discuss the novel transgenic reporter mouse models for in vivo biophotonic/bioluminescence imaging of glial responses to ischemic injury. Generation of these novel model systems has allowed visualization and analysis of the processes such as neuroinflammation and repair from the brains of live animals.

\section{Brain response to ischemic injury}

Brain ischemic injury is comprised of two major pathophysiological processes, a loss of oxygen and glucose supply induced by vascular occlusion is followed by a series of acute metabolic changes. This consequently causes the collapse of energy-producing processes resulting in the disintegration of cell membranes and neuronal death at the center/core of infarction. In the center or core of the ischemic territory, cell death progresses within minutes as a result of acute blood flow deficits, low ATP levels, ionic disruption and severe metabolic failures [54, 74]. The peripheral zones within the flow-compromised territory, called the ischemic penumbra, suffer milder early damage due to a residual perfusion from the collateral blood vessels [90]. To define penumbra in hemodynamic terms, this is the region where local cerebral blood flow is reduced to an intermediate degree, i.e, $20-40 \%$ of control values [44]. In the centre of the ischemic region, cells undergo anoxic depolarization and they never repolarize, while in the penumbral region, the cells can repolarize at the expense of further energy consumption and depolarize again in response to elevated levels of extracellular glutamate and potassium ions $\left[\mathrm{K}^{+}\right]$. Such repetitive depolarizations, called "peri-infarct depolarizations", lead to the increased release of the excitatory neurotransmitter glutamate with ensuing excitotoxic cell damage [55]. Ultimately, the severity of functional and structural (irreversible) changes in the brain caused by ischemia will depend on its degree and duration. Here it is important to note that the brain response to ischemia is not a simple pathological event. It includes the activation of several pathophysiological pathways that may be associated simultaneously with the processes of neuronal death and/or neuroregeneration. As previously suggested by Dirnagl and colleagues [34], brain damage following transient or permanent ischemia results from a series of pathophysiological events that evolve in time and space. Early pathophysiological events start a few minutes after stroke and last for several hours. They include acute necrosis in the centre of infarction, followed by peri-infarct depolarizations, excitotoxicity and oxidative stress [34, 87]. Experimental evidence suggests that neurons at the border of the ischemic territory can survive for many hours, even days after an ischemic insult [30]. The delayed tissue response to brain ischemia encompasses processes such as inflammation and apoptosis. These delayed processes are initiated several hours after the initial ischemic attack and may persist for several days even weeks after stroke. At present, it is not exactly clear how these events may affect post stroke recovery and brain regenerative responses.

\section{Brain plasticity and post stroke recovery}

In cerebral ischemia, the initial pathological events associated with direct cell death are followed by the activation of regenerative processes for days, weeks or even months following initial stroke [27, 138]. After an ischemic attack, a majority of stroke patients exhibit certain levels of motor weakness and sensory disturbances; however, over time, most will show a certain degree of functional recovery [28, 63]. The results of several animal and human studies on stroke have revealed that post stroke recovery and restoration of function may be explained by brain reorganization and brain plasticity [63, 82, 126, 129]. As suggested by Lledo and colleagues [86], brain plasticity refers to the brain ability to change its structure and function during maturation, learning, environmental changes and pathology. Altogether, brain plasticity ultimately involves all the mechanisms implicated in the capacity of the brain to adjust and remodel itself in response to environmental requirements, experience, skill acquisition and new challenges including brain lesions. For example, starting within the minutes following ischemia, rapid changes are observed in the number and the length of dendritic spines. Loss of dendritic spines observed at the excitatory synapses may reflect an early adaptive response of vulnerable ischemic neurons in the peri-infarct region $[19,51]$. The initial loss, at the 
later time points, is then followed by the re-establishment of the dendritic spine synapses and its dynamic and rapidly changing milieu represents a potential substrate for functional recovery [27]. Loss of function following ischemic stroke is determined by neuronal death within the center of the infarcted zone, but also with the dysfunction of the cells in the hypoperfused areas (penumbra region) surrounding the ischemic lesion. Additional loss of function in the neuroanatomically more remote areas is believed to be due to loss of connections, some major metabolic changes and altered neuron transmission [138, 140]. Conversely, the molecular mechanisms of neuroplasticity that would underlie efficient functional recovery and compensate for a loss of function should therefore include unmasking the silent pathways and/or synapses as well as the recruitment of alternative parallel pathways which would require axonal sprouting and the formation of new synapses from surviving neurons. The results of the recent studies by Brown et al. and Winship and Murphy [19, 139] further confirm these views. Taking advantage of an in vivo imaging approach and the transgenic mouse model expressing YFP in layer 5 cortical neurons, they demonstrated that the initial rapid changes in the dendritic response were followed, at later time points, by functional reorganization and rewiring of surviving neurons several months after initial stroke [19, 139].

Functional recovery after cerebral ischemia has been associated with brain plasticity. However, the exact causal link, the factors that can influence plasticity and its temporal characteristics have not yet been completely established. To date, most of the research efforts to enhance spontaneous post-injury plasticity and function recovery after stroke have been oriented towards controlled rehabilitation studies and enriched environment [17, 64, 100, 101], pharmacological and/or indirect electrical and transcranial magnetic stimulation of the brain, [16, 56] and more recently, cell based therapies $[52,69]$. The targeted research in this direction has provided us with some promising results; however, there is a growing line of evidence suggesting that in addition to previously mentioned approaches, the brain inflammatory response to ischemia and glial cells may play an important role in the modulation of post-ischemic synaptic plasticity and brain recovery $[49,136]$.

\section{Inflammatory response after stroke: a dual role?}

Although for many years, the central nervous system (CNS) has been considered to be an immune-privileged organ, it is now well accepted that the immune and the nervous system are engaged in bi-directional crosstalk [125]. Moreover, mounting evidence suggest that in the brain as in other organs, inflammatory cells could participate in tissue remodeling and reconstruction following injury. Experimentally and clinically, stroke is followed by an acute and prolonged inflammatory response characterized by the activation of resident glial cells, the production of inflammatory cytokines, as well as leukocyte and monocyte infiltration in the brain. These events may contribute to ischemic brain injury [34, 75, 79, 87]. However, whether post-ischemic inflammatory responses are deleterious or beneficial to brain recovery is presently a matter of debate.

To add to this controversy, in the past few years, several groups have reported conflicting results on the role of inflammation and effects of anti-inflammatory approaches in cerebral ischemia. For example, elevated levels of IL-6 in the circulation have long been associated with the severity of stroke [11, 134]. Barone et al. [9] demonstrated that blocking endogenous $\mathrm{TNF} \alpha$ significantly reduced infarct size in rats with the permanent or transient middle cerebral artery occlusion. A role for IL- $1 \beta$ in the pathogenesis of ischemic brain damage is supported by increased infarction resulting from intracerebroventricular injection of this cytokine in rat brain and conversely, neuroprotective effects of interleukin-1 receptor antagonist [88, 114, 141]. In addition, short-term treatments with the antimicrobial/antiinflammatory agent minocycline alone or in combination conferred neuroprotection in experimental stroke [3, 137, 142, 143]. The treatments with nonsteroid anti-inflammatory agents that selectively or non-selectively inhibit cyclooxygenase 2 (COX-2), in some studies, also conferred neuroprotection in experimental cerebral ischemia [110, 132]. Altogether these results suggest that inflammation after stroke is detrimental for brain. However, to date, the role of post-ischemic inflammation and the pro-inflammatory cytokines is cerebral ischemia is not yet completely elucidated. The study by Clark et al. demonstrated that infarct size and neurological function were not different in animals deficient in IL-6 after transient CNS ischemia. This suggests that IL-6 does not have a direct influence on acute ischemic injury [24]. On the other hand, the results of several other studies revealed that the deletion of cytokine and/ or cytokine receptors for $\mathrm{TNF} \alpha$ and/or IL-6 resulted in a significantly larger amount of necrotic tissue, higher mortality and poor functional outcome following experimental ischemia and brain injury [20, 42, 124, 128]. Findings of Carlson et al. [23], using in vitro conditions also suggested a possible neuroprotective role of different cytokines. To add to this confusion, and in contradiction to some previous results, Hara et al. [50] reported that there was no beneficial effect on temporary focal cerebral ischemia in rats following selective inhibition of COX-2. Moreover, treatments with different classes of $\mathrm{COX}$ inhibitors had negative effects on the proliferation of neuronal progenitor cells in dentate gyrus following cerebral ischemia [120, 121]. Finally, recent studies demonstrated beneficial effects of 
pro-inflammatory cytokines, a granulocyte-macrophage colony-stimulating factor (GM-CSF) and macrophage colony stimulating factor (MCSF) in the treatment of experimental cerebral ischemia [79, 122, 127].

The main effectors of the immune response in the brain are glial cells, in particular activated microglia. Although, it is generally believed that the activated microglial cells in ischemic injury are neurotoxic, the results of several recent studies revealed, that in certain conditions microglia may exert neuroprotection [70,71], be involved in the regulation of regenerative state and the remodeling of the brain by producing neurotrophic molecules such as brain-derived neurotrophic factor (BDNF) [10, 93, 95], insulin growth factor 1 (IGF-1) $[79,102]$ and depending on the type of stimuli, several other growth factors [49]. Moreover, the studies from Neumann and colleagues using organotypic hippocampal brain slices exposed to oxygen/glucose deprivation (OGD), an in vitro model of stroke, clearly demonstrated that activated microglial cells can protect neurons by direct physical contacts [97] and/or by the engulfment of activated and neurotoxic polymorphonuclear neutrophils (PMNs) [98]. Altogether, these findings further support the view that the close brain-immune system interactions are highly relevant for functional outcome after stroke. An additional interesting point recently revealed by Lai and Todd [78] is that severity of neuronal injury may in fact influence whether microglia would release toxic or neuroprotective effects. However, the ability of glial cells, in particular, activated microglia, to produce and secrete growth factors raises the possibility that inflammatory cells may have a role in tissue remodeling after cerebral ischemia and, therefore, affect brain plasticity and functional recovery after stroke.

\section{Inflammatory response, brain plasticity and functional recovery after stroke}

At present, the complete temporal and spatial dynamics of post-ischemic inflammatory response is not known. The recent results suggest that the inflammatory response after ischemia has a marked chronic component. Namely, Ekdahl and coworkers [38] reported an increased number of activated microglial cells up to 16 weeks after $2 \mathrm{~h}$ middle cerebral artery occlusion (MCAO) stroke model in rats. Using the novel transgenic mouse model recently developed in our laboratory, we were able to visualize/detect activated microglial cells several months after moderate (60 min) MCAO occlusion in mice [26]. Together, these findings suggest that an active post-ischemic inflammatory response may lasts much longer than initially thought and may temporally coincide with the processes of post-ischemic recovery. This raises the possibility that inflammatory response after ischemia may play an active role in CNS regeneration.

Glial cells and trophic factors

Activated glial cells, in particular microglia express and secrete a broad spectrum of different molecules such as cytokines, neuronal growth factors, neurotransmitters (glutamate) and diffusible molecules such as NO which are known to regulate synaptic functions $[2,34,43,48,113$, 116]. Microglial cells are the main effectors of the immune response following brain injuries and several hours after stroke, the resident microglial cells become activated, accumulate at the lesion site, in the penumbra region and proliferate. Using a transgenic mouse model for the selective ablation of proliferating microglial cells, we recently demonstrated that the subset of resident microglial cells in proliferation express and secrete neurotrophic growth factors such as IGF-1 [79]. Conversely, the ablation of the proliferating microglial cells was associated with a significant decrease in IGF-1 levels. The microglial IGF-1 expression has been also recently reported by Ohtaki et al. [104].Using a different experimental approach, Imai and colleagues [58] demonstrated that exogenous transplantation of microglial cell into ischemic brain resulted with an increase in the levels of BDNF. Finally, that activated and proliferating glial cells may indeed represent an important source of neutrophins in post-ischemic brain has been recently demonstrated by Tonchev et al. [133]. In their work, the in situ studies performed on ischemic primate brain revealed that ischemic injury resulted in a strong up-regulation of trkA and trkB receptors (NGF and BNDF receptors, respectively), in the pyramidal neurons of ischemic hippocampus, thus suggesting that activation and proliferation of resident glial cells following ischemic injury, as a part of the inflammatory response, may play an important role in modulation of brain plasticity via secretion of trophic molecules [133].

\section{Cytokines and brain plasticity}

There is substantial evidence demonstrating that activated microglial cells in response to ischemia have the potential of releasing several pro-inflammatory cytokines such as TNF-alpha, IL-1 $\beta$ and IL-6, as well as other potential cytotoxic molecules including nitric oxide, reactive oxygen species and prostanoids $[34,57,119]$. Cytokines are regulatory proteins that had been traditionally viewed as immune modulators. However, experimental evidences suggest that they play an important role as a neuromodulators following CNS injuries. The results of several experimental studies demonstrated that pro-inflammatory cytokines may affect synaptic plasticity. The current view is that at low "physiological" levels, cytokines and others immune mediators 
may be instrumental for maintenance of neuroplasticity [31, 135]. On the other hand, after injuries such as cerebral ischemia, the induction and the over-expression of these molecules that occurs as a part of neuroinflammatory response may result in the impairment of synaptic plasticity and the associated neurodegeneration. Earlier studies demonstrated inhibitory effects of IL-1 $\beta$ on the hippocampal long-term potentiation (LTP) [67]. The exact mechanisms of the inhibitory effects of IL-1 $\beta$ on synaptic plasticity are not completely elucidated; however, in vitro studies performed on pharmacologically isolated NMDA receptors revealed that administration of IL-1 $\beta$ was associated with significant decrease in NMDA receptor excitatory post-synaptic potentials $[14,41]$. Similar effects with regard to LTP were observed in the transgenic mouse model over-expressing IL-6. Cerebral over-expression of IL-6 in GFAP-IL6 transgenic mouse models was associated with significant reduction of LTP in the hippocampus [15]. Conversely, the experiment performed on freely moving rats demonstrated that blockade of endogenous IL-6 using a neutralizing antiIL6 antibody was associated with marked prolongation of LTP and significant improvement in long-term memory [7]. Surprisingly, the effects of the pro-inflammatory cytokine TNF- $\alpha$ on synaptic plasticity are somehow less clear. TNF- $\alpha$ is considered to be a crucial pro-inflammatory cytokine involved in the crosstalk between the immune system and the brain. It has been demonstrated that TNF- $\alpha$ is able to increase the expression of AMPA receptors and therefore potentially strengthen the glutamatergic synapse [12]. However, the series of experimental studies on the role of $\mathrm{TNF}-\alpha$ on synaptic plasticity yielded contradicting results. While functional studies employing transgenic mouse models lacking TNFR1 and R2 receptors revealed normal synaptic plasticity [130], Butler and colleagues [21] reported inhibitory effects of TNF- $\alpha$ on LTP, thus suggesting that the precise role of TNF- $\alpha$ in the modulation of synaptic plasticity is far more complex than initially thought. Altogether, we can summarize here that up-regulation of major proinflammatory cytokines after ischemia confers inhibition on the early changes in the injury-induced synaptic plasticity. It is important to mention however, that transcriptional activation for the genes encoding for above-mentioned cytokines peaks at 12-24 h after ischemia [53, 79, 103] and declines at the later time points. Hence, the direct inhibitory effects of pro-inflammatory cytokines on synaptic plasticity should be evident within the first $72 \mathrm{~h}$ after ischemia. At the later time points after stroke (several days and weeks after injuries), the role of pro-inflammatory cytokines in the modulation of synaptic plasticity and thus potentially brain plasticity/recovery is far less clear. One of the possibilities is that pro-inflammatory cytokines may still be involved in modulation of brain plasticity at the later time points via the regulation of different gene/protein expression. After ische- mia, proteins such as growth associated protein-43 (GAP43), nestin, tubuline, peripherin, etc., that are normally expressed in the developing brain and suppressed in the adult CNS, become up-regulated [13, 27, 84, 96]. The results of our previous studies demonstrated that peripherin, one of developmentally highly expressed protein is strongly up-regulated in CNS neurons after ischemia [13]. Peripherin is a $57-\mathrm{kDa}$ type III intermediate filament [112] and previous work suggests that is plays an important role in neurite elongation during development [40]. In the adult, peripherin is almost exclusively expressed in the neurons of the peripheral nervous system (PNS), and in the CNS its expression is limited to neurons with direct projections to periphery [18, 109, 115], while normally it is undetectable in most CNS neurons $[13,35]$. Although at present the biological functions of peripherin are still poorly understood, evidence suggests that in response to nerve injuries, peripherin may be involved in neuronal regeneration. More importantly, previous work using in vitro and in vivo model systems revealed that peripherin expression can be induced and modulated by pro-inflammatory cytokines such as IL-6 $[13,81,131]$ and LIF $[13,35]$. Functional analysis revealed that up-regulation of peripherin has been associated with the marked alterations in the synaptic plasticity in CA1 and CA3 regions of the hippocampus [76]. These results may provide evidence for a more direct involvement of the proinflammatory cytokines in the brain remodeling and plasticity. However, caution is required since persistent and chronic induction of cytoskeletal proteins may lead to aberrant structural changes and pathological alterations in brain plasticity [32, 66, 111]. For example, as shown in Fig. 1, a chronic inflammatory response may lead to a pathological expression of cytoskeletal proteins, such as peripherin, in degenerating neurites surrounding amyloid plaques in the mouse model of Alzheimer's disease (Fig. 1). A question here is whether these cytoskeletal alterations may in part explain a known susceptibility of stroke patients to develop Alzheimer's type of dementia?

\section{How brain inflammatory response to ischemic injury may affect neurogenesis and brain recovery?}

Pathological conditions such as cerebral ischemia can strongly induce and/or promote adult neurogenesis [29, 61, $62,73]$. In specifically restricted areas of the mammalian brain such as dentate gyrus of subventricular zone (SVZ), the new functional neurons are generated from the endogenous pools of neuronal stem cells throughout the life [91]. Following different types of brain injuries including ischemia, the proliferative response is markedly increased in these regions. Moreover, post-ischemia, new neurons could be also found in the striatum and cerebral cortex, brain 
Fig. 1 Chronic inflammation is associated with the time and agedependent increase in peripherin expression in the brains of the mouse model of Alzheimer's disease. Immunostaining with the anti-peripherin antibody (AB1530, 1:1,000 dilution, Chemicon) of the coronal brain sections revealed formation of the peripherin accumulations in degenerating neurites (black arrows) surrounding betaamyloid plaques (Congo red staining). The accumulations were detected only in older 10-month-old transgenic mice $(\mathbf{c}, \mathbf{d})$, while the brains of the pre-symptomatic 5-month-old transgenic mice were devoid of plaques and peripherin immunoreactivities $(\mathbf{a}, \mathbf{b})$. Scale bars $\mathbf{a}, \mathbf{c}=500 \mu \mathrm{m}$; $\mathbf{c}, \mathbf{d}=50 \mu \mathrm{m}$
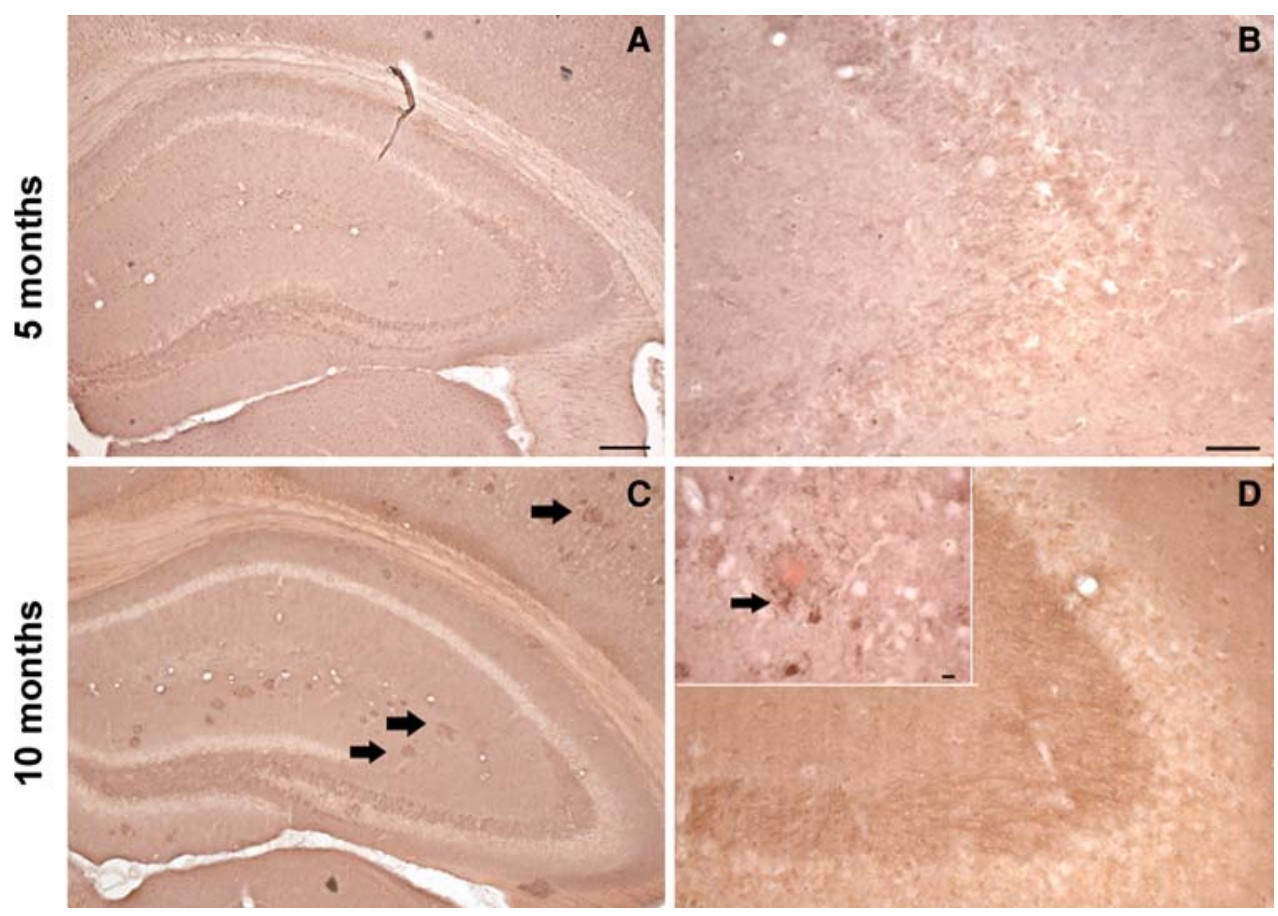

regions that are normally not involved in adult neurogenesis [29, 61, 62, 73]. These findings strongly suggests that pathological conditions may trigger the processes of endogenous neurogenesis in brain regions where adults neurogenesis is normally not existent. However, the functional benefits of such a response are presently a matter of numerous debates. Furthermore, here it is important to mention that these observations, in particular, with regard to newly formed cortical neurons stem from rodents and have not been confirmed in humans.

A current view is that injury-induced neurogenesis may carry a significant impact on post-ischemic brain plasticity and recovery. At present, the precise molecular mechanisms involved in the induction and/or regulation of the post-injury neurogenesis remain unknown. Mounting evidence suggests that inflammation may play an important role. By using two different experimental approaches, the initial work by Monje et al. [94] and Ekdahl et al. [37] revealed that inflammation has a detrimental effect on adult brain neurogenesis, while Liu and colleagues [85] demonstrated that long-term treatment with anti-inflammatory and antimicrobial agent minocycline after stroke significantly increases the number of newborn neurons in the dentate gyrus and improves functional recovery. New evidence, however, suggest that the role of the inflammatory response on adult neurogenesis is far more complex than initially thought and may additionally depend on the direct interactions between progenitors and activated glial cells [38]. It has been demonstrated that following injuries, glial cells, in particular microglia, depending on the activation state, can adopt different phenotypes (neurotoxic vs. neuroprotec- tive). For instance, treatment of microglial cells with the cytokine IL-4 would change the phenotype of activated microglial from TNF- $\alpha$ to IGF-1 producing cells [22]. We observed similar findings following the treatment of activated microglial cells with MCSF [79]. Namely, changing the state of microglial activation from highly-activated to proliferating was associated with the significant decrease in TNF- $\alpha$ production and the increase in IGF-1 secretion [79]. IGF-1 is a known anti-apoptotic factor and recent reports suggest that it plays an important role in promotion of proliferation and differentiation of neuronal progenitors [65, 107, 145]. Contrary to IGF-1, the studies performed on the transgenic animals lacking TNFR1 revealed that TNFR1 acts as a negative regulator of neuronal progenitors in hippocampus and in SVZ area after stroke [59, 60].

TLRs, response to ischemic injury and neurogenesis

To date, most of the studies exploring interactions between inflammation, neuronal damage/neurogenesis and brain plasticity have been focused on the role of different proinflammatory cytokines and trophic factors; however, relatively little is known about the role and possible interactions between the innate immune response, cerebral ischemia, and brain recovery. The brain response to ischemia is characterized by a reactive microgliosis $[33,75,77]$ that is associated with a robust induction of the transmembrane receptor Toll-like receptor 2 (TLR2). While it has been widely established that TLRs are the key mediators in the response to invading pathogens, there is a growing line of evidence suggesting that TLRs can be activated by 
endogenous "danger signals" released from the injured or necrotic cells. More particularly, TLR2 and TLR4 can interact with endogenous alarm signals such as heat shock proteins (Hsp60 and 70), extracellular breakdown product of hyaluron lipoproteins, etc., suggesting that TLRs may be involved in the regulation of inflammatory response following brain injuries [5, 47, 106] and neurodegeneration [99, 105]. Recent studies demonstrated that TLRs, in particular TLR2 may be an important mediator of CNS ischemic injury [83, 147]. The induction of TLR2 has been also observed in the activated microglial cells in other types of brain injuries. For example, TLR2 is strongly induced in the microglial cells situated in denervated zones of the hippocampus after following stereotaxic transsection of the axons in the mouse entorhinal cortex [6]. Interestingly, in the same experimental paradigm, the TLR2 deficiency in mice was associated with an early delay in microglial proliferation [6]. However, at present little is known about the long-term role of TLR2 signaling and microglial activation in the brain response to injury. The results of our recent study revealed a very interesting and potentially long-term role of TLR2 signaling and microglial activation in the brain response to ischemic injury. Namely, taking advantage of a mouse model recently developed in our laboratory (TLR2 reporter mouse) in which we can longitudinally visualize TLR2 induction/microglial activation, we observed several very interesting primary findings [80]. First, the TLR2 response to cerebral ischemia was associated with a marked chronic component, which may last for several months after initial stroke. Moreover, the inflammatory response was not restricted to the site of injury being also evident in the olfactory bulb (OB) [80]. As expected, following ischemia, the TLR2 induction was predominately observed in activated microglial cells. Another interesting detail is that, in addition to activated glial cells the TLR2 immunoreactivity was also detected in the subset of doublecortin (DCX) positive cells in OB as well as in the small subset of stressed neurons situated with the center of ischemic lesion. These findings are in agreement with earlier reports by Rolls et al. [117] where TLR2 expression was detected in the cells expressing early neuronal markers such as DCX. Moreover, TLR2 deficiency in mice was associated with significantly impaired neurogenesis [117], thus suggesting that TLR2 signaling may represent an important link for cross dialog between injury-induced innate immune response and brain neurogenesis/recovery.

However, the role of TLRs and in particular TLR2 in brain ischemia is far from being elucidated. In the recent work, Lehnardt et al. [83] and Ziegler et al. [147] reported smaller infarction size in the mice lacking TLR2 receptors, yet, on the other hand, the same signaling pathway has been reported instrumental for brain neurogenesis [117]. From the experimental results, it is conceivable that in acute response to injuries activated microglial cells may play an early detrimental role that can be converted into supportive role in the later, chronic phase of the brain response to ischemic injury. Supportive of that view are the results of numerous pharmacological studies reporting neuroprotective effects of the early anti-inflammatory treatments after stroke. An additional example of time-dependent result discrepancies in cerebral ischemia is the role of matrix metalloproteases (MMPs). While early inhibition of MMPs conferred neuroprotection [4], data by Zhao and coworkers [144] revealed that late inhibition of MMPs was associated with an increase in the size ischemic injury and impaired functional recovery; thus, again suggesting a time-dependent nature and/or functional role of inflammatory response in brain ischemia [1]. Therefore, to better understand the temporal and the spatial dynamics of the post-ischemic inflammation, there is a need to develop novel model systems. In our laboratory, we have developed an experimental approach (in vivo bioluminescence and fluorescence) to longitudinally image and analyze astrocyte and microglial responses from the brains of living animals following acute injuries, such as ischemia, and in the model of chronic neurodegenerative disorders [26, 68, 146]. Moreover, using this imaging approach we were able to analyze glial responses and a biocompatibility of several different nanoparticles administered in the brain [89].

\section{Live imaging: development of novel experimental approaches to study inflammation and brain recovery}

In recent years, imaging strategies employing reporter molecules have been developed to study biological processes as they occur in living animals or as they appear in real time in cell assays. These new technologies are based on sources of light emitted from fluorescent proteins or luminescent enzymes. One class of reporter genes that have been used for in vivo detection is fluorescent protein such as GFP. For example, Pan et al. [108] reported the in vivo visualization of axons in transgenic mice expressing a Thy-1 promoter/ GFP construct. Another approach uses bioluminescence enzymes like the firefly luciferase (Fluc) that emits light when provided with the appropriate substrate [25, 36]. Bioluminescence is a chemical reaction and no external excitation is needed to obtain the signal. Luciferase catalyzes the cleavage of the substrate luciferin in presence of oxygen and ATP, resulting in the emission of light with broad spectral emission that peaks at $560 \mathrm{~nm}$ with substantial fraction of light above $600 \mathrm{~nm}$ making it suitable for in vivo imaging. The photons emitted by Fluc reporter activity pass the host tissue and are detectable at the surface with sensitive photo detectors based on a CCD camera (see Fig. 2). The bioluminescence produces a better signal-to-noise ratio 


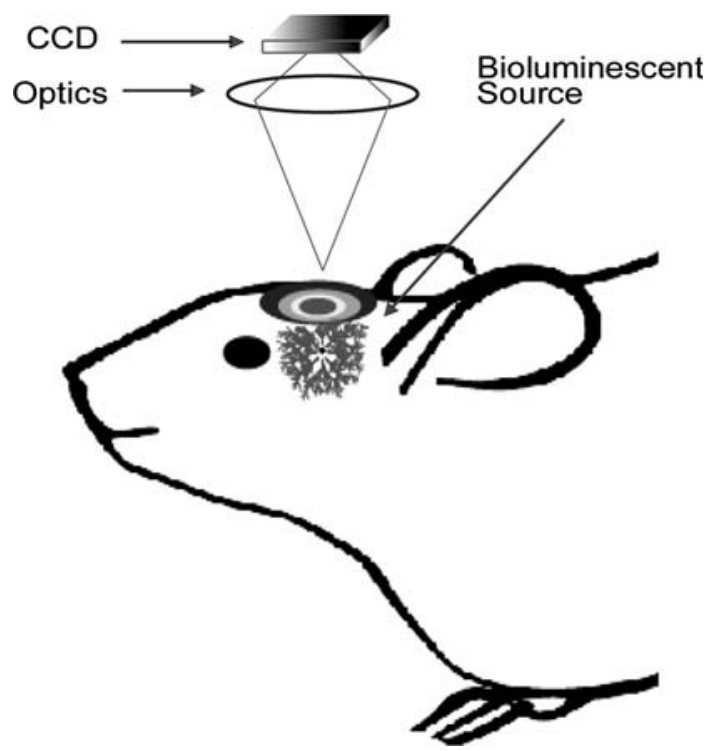

Fig. 2 Schematic representation of in vivo biophotonic/bioluminescence imaging from the brains of transgenic reporter mice

than fluorescence in living animals. It is highly sensitive with no background of light emission from rodent tissues and luciferin is non-toxic. However, the in vivo bioluminescence and whole animal imaging is not without the pitfalls. One major weaknesses of this approach is the relatively low signal-to-signal resolution. Further, during in vivo imaging, the experimental animals are shortly anesthetised (for few minutes) which can influence neuronal activity. In addition, because the imaging protocols and the acquisition of the bioluminescent images may last for several minutes, (in general $1-3 \mathrm{~min}$ ), this method is not suitable for in vivo imaging of the fast cellular and the metabolic changes. An alternative approach is in vivo high resolution optical imaging and multiphoton microscopy [92]. This technique has a far superior microscopic resolution; however, a major weakness of this approach is the relatively low tissue penetration $(\sim 500 \mu \mathrm{m})$ that limits the imaging of the brain after ischemia to the examination of the cerebral cortex $[72,123]$.
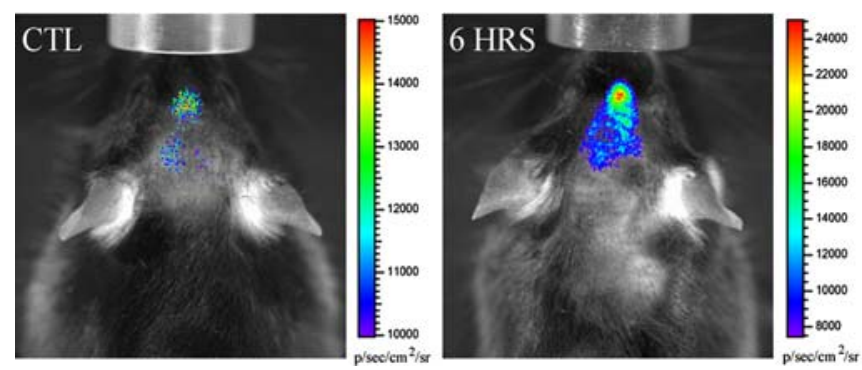

Fig. 3 Representative photographs of single transgenic TLR2-luc/gfp reporter mouse imaged at different time points following 1-h transient MCAO. Real-time imaging of TLR2 response/microglial activation reveals a long-term induction of inflammatory signals (up to 3-months
Keeping in mind advantages and disadvantages of different in vivo optical imaging approaches, we have developed and validated in a stroke model several transgenic mouse model of bioluminescence and fluorescence for time-lapse imaging of processes associated with CNS neuroinflammation, in particular, microglia [80] and astrocyte activation $[26,68,146]$. To investigate the TLR2 response and associated microglial activation in the living brain, we generated a transgenic mouse model bearing the dual reporter system luciferase and green fluorescent protein (GFP) under the transcriptional control of a murine TLR2 promoter. In this mouse model, transcriptional activation of TLR2 (bioluminescence photon emission) can be visualized in the brains of live animals using biophotonic/bioluminescence imaging and high resolution CCD camera (Figs. 2, 3) [80]. After experimental stroke, we were able to image and analyze the innate immune response and microglial activation from the same living mouse over a 3-4 month time-period (see Fig. 3).The advantage of a dual reporter system is that following in vivo bioluminescence imaging in the same animal using GFP as a reporter, we can analyze the same subpopulation of the cells (activated microglia) using microscopic resolution [80]. Because inflammation after stroke is a dynamic process with an important spatial as well as temporal component, it is our view, that these mouse models will provide unique tools for additional understanding of disease pathology and brain response to ischemic injury and can be very valuable in longitudinal responses to drug testing.

\section{Conclusion}

In conclusion, in the presented work, we sought to discuss how post-ischemic inflammation may affect brain plasticity. The answer to this question is rather complex and it is beyond the scope of just one review. As described, evidence suggests that post-ischemic inflammation contributes to brain injury and to the expansion of the ischemic lesion. On the other hand, adequate immune response after injuries

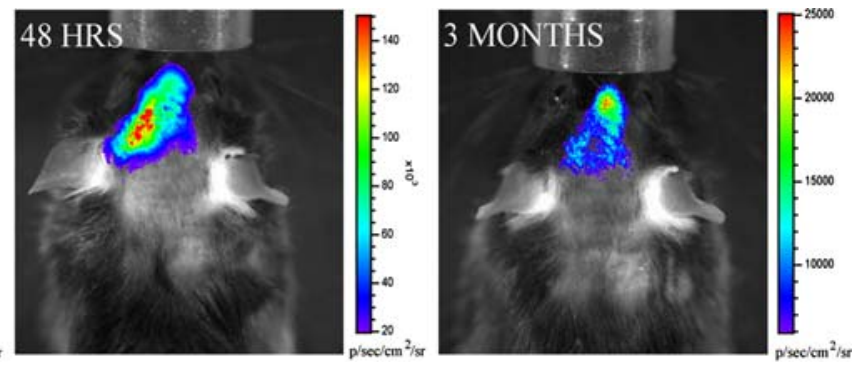

post-ischemia). Photographs show different sites of TLR2 induction in the brain: one in a frontal area and one at the site of the ischemic lesion. The color calibrations at the right are photon counts. Note the occurrence of different scales in various ranges 
Fig. 4 Simplified presentation of the key players and potential modulators of post-ischemic inflammation and the brain plasticity and recovery

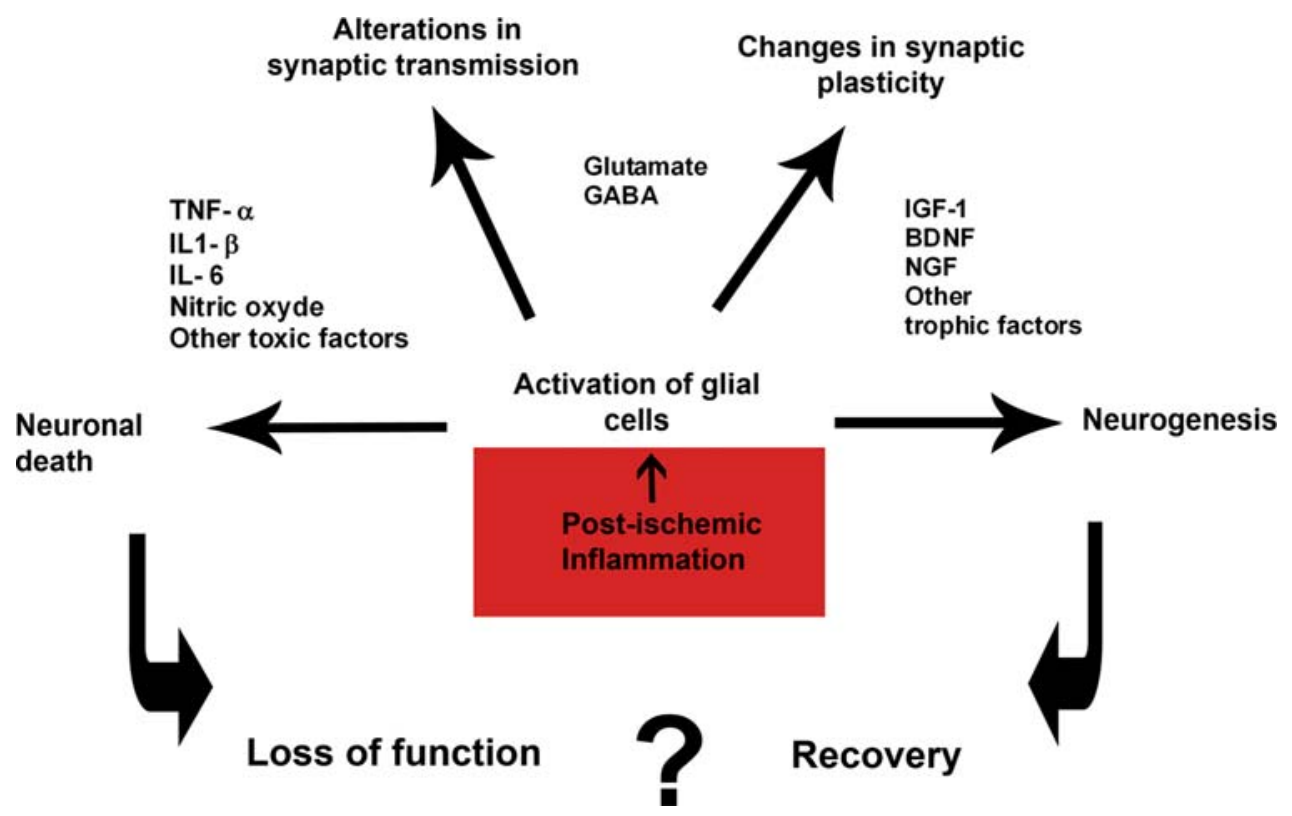

anges in synaptic plasticity

Nitric oxyde is instrumental in orchestrating brain regeneration and repair suggesting that the role of inflammation in the brain response to ischemic injury goes beyond simple good-versus-bad dichotomy (see Fig. 4). It is our hope that novel experimental approaches (and novel animal models) such as in vivo biophotonic/bioluminescence imaging will provide a novel knowledge on the complex spatial and temporal nature of the inflammatory response in the brain. Finally, development of novel in vivo imaging tools may facilitate development of new therapeutic strategies for stroke patients.

Acknowledgments This work was supported by the Canadian Institutes of Health Research (CIHR), operating grants No. 142739 and 171955, and the funds from Quebec Transgenic Research Network (QTRN). J.K. is recipient of the Career Award from the R\&D Health Research Foundation and CIHR. M.L-H. is recipient of the CIHR Canada Doctoral Scholarship Award.

Open Access This article is distributed under the terms of the Creative Commons Attribution Noncommercial License which permits any noncommercial use, distribution, and reproduction in any medium, provided the original author(s) and source are credited.

\section{References}

1. Agrawal SM, Lau L, Yong VW (2008) MMPs in the central nervous system: where the good guys go bad. Semin Cell Dev Biol 19:42-51. doi:10.1016/j.semcdb.2007.06.003

2. Allan SM, Rothwell NJ (2001) Cytokines and acute neurodegeneration. Nat Rev Neurosci 2:734-744. doi:10.1038/35094583

3. Arvin KL, Han BH, Du Y et al (2002) Minocycline markedly protects the neonatal brain against hypoxic-ischemic injury. Ann Neurol 52:54-61. doi:10.1002/ana.10242

4. Asahi M, Asahi K, Jung JC et al (2000) Role for matrix metalloproteinase 9 after focal cerebral ischemia: effects of gene knockout and enzyme inhibition with BB-94. J Cereb Blood
Flow Metab 20:1681-1689. doi:10.1097/00004647-20001200000007

5. Asea A (2008) Heat shock proteins and toll-like receptors. Handb Exp Pharmacol 111-127

6. Babcock AA, Wirenfeldt M, Holm T et al (2006) Toll-like receptor 2 signaling in response to brain injury: an innate bridge to neuroinflammation. J Neurosci 26:12826-12837. doi:10.1523/ JNEUROSCI.4937-05.2006

7. Balschun D, Wetzel W, Del Rey A et al (2004) Interleukin-6: a cytokine to forget. FASEB J 18:1788-1790

8. Barber PA, Auer RN, Buchan AM, Sutherland GR (2001) Understanding and managing ischemic stroke. Can J Physiol Pharmacol 79:283-296. doi:10.1139/cjpp-79-3-283

9. Barone FC, Arvin B, White RF et al (1997) Tumor necrosis factor-alpha. A mediator of focal ischemic brain injury. Stroke 28:1233-1244

10. Batchelor PE, Liberatore GT, Wong JY et al (1999) Activated macrophages and microglia induce dopaminergic sprouting in the injured striatum and express brain-derived neurotrophic factor and glial cell line-derived neurotrophic factor. J Neurosci 19:1708-1716

11. Beamer NB, Coull BM, Clark WM, Hazel JS, Silberger JR (1995) Interleukin-6 and interleukin-1 receptor antagonist in acute stroke. Ann Neurol 37:800-805. doi:10.1002/ana. 410370614

12. Beattie EC, Stellwagen D, Morishita W et al (2002) Control of synaptic strength by glial TNFalpha. Science 295:2282-2285. doi:10.1126/science.1067859

13. Beaulieu JM, Kriz J, Julien JP (2002) Induction of peripherin expression in subsets of brain neurons after lesion injury or cerebral ischemia. Brain Res 946:153-161. doi:10.1016/S00068993(02)02830-5

14. Bellinger FP, Madamba S, Siggins GR (1993) Interleukin 1 beta inhibits synaptic strength and long-term potentiation in the rat CA1 hippocampus. Brain Res 628:227-234. doi:10.1016/00068993(93)90959-Q

15. Bellinger FP, Madamba SG, Campbell IL, Siggins GR (1995) Reduced long-term potentiation in the dentate gyrus of transgenic mice with cerebral overexpression of interleukin-6. Neurosci Lett 198:95-98. doi:10.1016/0304-3940(95)11976-4

16. Biegon A, Fry PA, Paden CM et al (2004) Dynamic changes in $\mathrm{N}$-methyl-D-aspartate receptors after closed head injury in mice: implications for treatment of neurological and cognitive deficits. 
Proc Natl Acad Sci USA 101:5117-5122. doi:10.1073/pnas. 0305741101

17. Biernaskie J, Chernenko G, Corbett D (2004) Efficacy of rehabilitative experience declines with time after focal ischemic brain injury. J Neurosci 24:1245-1254. doi:10.1523/JNEUROSCI. 3834-03.2004

18. Brody BA, Ley CA, Parysek LM (1989) Selective distribution of the $57 \mathrm{kDa}$ neural intermediate filament protein in the rat CNS. J Neurosci 9:2391-2401

19. Brown CE, Wong C, Murphy TH (2008) Rapid morphologic plasticity of peri-infarct dendritic spines after focal ischemic stroke. Stroke 39:1286-1291. doi:10.1161/STROKEAHA.107. 498238

20. Bruce AJ, Boling W, Kindy MS et al (1996) Altered neuronal and microglial responses to excitotoxic and ischemic brain injury in mice lacking TNF receptors. Nat Med 2:788-794. doi:10.1038/ nm0796-788

21. Butler MP, O'Connor JJ, Moynagh PN (2004) Dissection of tumor-necrosis factor-alpha inhibition of long-term potentiation (LTP) reveals a p38 mitogen-activated protein kinasedependent mechanism which maps to early-but not late-phase LTP. Neuroscience 124:319-326. doi:10.1016/j.neuroscience. 2003.11.040

22. Butovsky O, Talpalar AE, Ben-Yaakov K, Schwartz M (2005) Activation of microglia by aggregated beta-amyloid or lipopolysaccharide impairs MHC-II expression and renders them cytotoxic whereas IFN-gamma and IL-4 render them protective. Mol Cell Neurosci 29:381-393. doi:10.1016/j.mcn.2005.03.005

23. Carlson NG, Wieggel WA, Chen J et al (1999) Inflammatory cytokines IL-1 alpha, IL-1 beta, IL-6, and TNF-alpha impart neuroprotection to an excitotoxin through distinct pathways. J Immunol 163:3963-3968

24. Clark WM, Rinker LG, Lessov NS et al (2000) Lack of interleukin-6 expression is not protective against focal central nervous system ischemia. Stroke 31:1715-1720

25. Contag CH, Bachmann MH (2002) Advances in in vivo bioluminescence imaging of gene expression. Annu Rev Biomed Eng 4:235-260. doi:10.1146/annurev.bioeng.4.111901.093336

26. Cordeau P Jr, Lalancette-Hebert M, Weng YC, Kriz J (2008) Live imaging of neuroinflammation reveals sex and estrogen effects on astrocyte response to ischemic injury. Stroke 39:935942. doi:10.1161/STROKEAHA.107.501460

27. Cramer SC, Chopp M (2000) Recovery recapitulates ontogeny. Trends Neurosci 23:265-271. doi:10.1016/S0166-2236(00) 01562-9

28. Cramer SC, Riley JD (2008) Neuroplasticity and brain repair after stroke. Curr Opin Neurol 21:76-82

29. Dash PK, Mach SA, Moore AN (2001) Enhanced neurogenesis in the rodent hippocampus following traumatic brain injury. J Neurosci Res 63:313-319. doi:10.1002/1097-4547(20010215) 63:4<313::AID-JNR1025>3.0.CO;2-4

30. Dereski MO, Chopp M, Knight RA, Rodolosi LC, Garcia JH (1993) The heterogeneous temporal evolution of focal ischemic neuronal damage in the rat. Acta Neuropathol 85:327-333. doi:10.1007/BF00227730

31. Di Filippo M, Sarchielli P, Picconi B, Calabresi P (2008) Neuroinflammation and synaptic plasticity: theoretical basis for a novel, immune-centred, therapeutic approach to neurological disorders. Trends Pharmacol Sci 29:402-412. doi:10.1016/ j.tips.2008.06.005

32. Di Filippo M, Tozzi A, Costa C et al (2008) Plasticity and repair in the post-ischemic brain. Neuropharmacology 55:353-362. doi:10.1016/j.neuropharm.2008.01.012

33. Dirnagl U (2004) Inflammation in stroke: the good, the bad, and the unknown. Ernst Schering Res Found Workshop 2004(47):87-99
34. Dirnagl U, Iadecola C, Moskowitz MA (1999) Pathobiology of ischaemic stroke: an integrated view. Trends Neurosci 22:391397. doi:10.1016/S0166-2236(99)01401-0

35. Djabali K, Zissopoulou A, de Hoop MJ, Georgatos SD, Dotti CG (1993) Peripherin expression in hippocampal neurons induced by muscle soluble factor(s). J Cell Biol 123:1197-1206. doi:10.1083/ jcb.123.5.1197

36. Doyle TC, Burns SM, Contag CH (2004) In vivo bioluminescence imaging for integrated studies of infection. Cell Microbiol 6:303-317. doi:10.1111/j.1462-5822.2004.00378.x

37. Ekdahl CT, Claasen JH, Bonde S, Kokaia Z, Lindvall O (2003) Inflammation is detrimental for neurogenesis in adult brain. Proc Natl Acad Sci USA 100:13632-13637. doi:10.1073/pnas. 2234031100

38. Ekdahl CT, Kokaia Z, Lindvall O (2008) Brain inflammation and adult neurogenesis: the dual role of microglia. Neuroscience

39. Endres M, Engelhardt B, Koistinaho J et al (2008) Improving outcome after stroke: overcoming the translational roadblock. Cerebrovasc Dis 25:268-278. doi:10.1159/000118039

40. Escurat M, Djabali K, Gumpel M, Gros F, Portier MM (1990) Differential expression of two neuronal intermediate-filament proteins, peripherin and the low-molecular-mass neurofilament protein (NF-L), during the development of the rat. J Neurosci 10:764-784

41. Feleder CP, Refojo D, Nacht S, Moguilevsky J (2000) Interleukin-1 inhibits NMDA-stimulated GnRH secretion: associated effects on the release of hypothalamic inhibitory amino acid neurotransmitters. Neuroimmunomodulation 7:46-50. doi:10.1159/ 000026419

42. Fontaine V, Mohand-Said S, Hanoteau N et al (2002) Neurodegenerative and neuroprotective effects of tumor necrosis factor (TNF) in retinal ischemia: opposite roles of TNF receptor 1 and TNF receptor 2. J Neurosci 22:RC216

43. Gibson CL, Coughlan TC, Murphy SP (2005) Glial nitric oxide and ischemia. Glia 50:417-426. doi:10.1002/glia.20143

44. Ginsberg MD (2003) Adventures in the pathophysiology of brain ischemia: penumbra, gene expression, neuroprotection: the 2002 Thomas Willis Lecture. Stroke 34:214-223. doi:10.1161/ 01.STR.0000048846.09677.62

45. Gladstone DJ, Black SE, Hakim AM (2002) Toward wisdom from failure: lessons from neuroprotective stroke trials and new therapeutic directions. Stroke 33:2123-2136. doi:10.1161/ 01.STR.0000025518.34157.51

46. Grotta J (2001) Combination Therapy Stroke Trial: recombinant tissue-type plasminogen activator with/without lubeluzole. Cerebrovasc Dis 12:258-263. doi:10.1159/000047713

47. Habich C, Baumgart K, Kolb H, Burkart V (2002) The receptor for heat shock protein 60 on macrophages is saturable, specific, and distinct from receptors for other heat shock proteins. J Immunol 168:569-576

48. Hanisch UK (2002) Microglia as a source and target of cytokines. Glia 40:140-155. doi:10.1002/glia.10161

49. Hanisch UK, Kettenmann H (2007) Microglia: active sensor and versatile effector cells in the normal and pathologic brain. Nat Neurosci 10:1387-1394. doi:10.1038/nn1997

50. Hara K, Kong DL, Sharp FR, Weinstein PR (1998) Effect of selective inhibition of cyclooxygenase 2 on temporary focal cerebral ischemia in rats. Neurosci Lett 256:53-56. doi:10.1016/ S0304-3940(98)00755-1

51. Hasbani MJ, Schlief ML, Fisher DA, Goldberg MP (2001) Dendritic spines lost during glutamate receptor activation reemerge at original sites of synaptic contact. J Neurosci 21:2393-2403

52. Hayashi J, Takagi Y, Fukuda H et al (2006) Primate embryonic stem cell-derived neuronal progenitors transplanted into ischemic brain. J Cereb Blood Flow Metab 26:906-914. doi:10.1038/ sj.jcbfm. 9600247 
53. Hill JK, Gunion-Rinker L, Kulhanek D et al (1999) Temporal modulation of cytokine expression following focal cerebral ischemia in mice. Brain Res 820:45-54. doi:10.1016/S00068993(98)01140-8

54. Hossmann KA (1994) Viability thresholds and the penumbra of focal ischemia. Ann Neurol 36:557-565. doi:10.1002/ana. 410360404

55. Hossmann KA (1996) Periinfarct depolarizations. Cerebrovasc Brain Metab Rev 8:195-208

56. Hummel F, Cohen LG (2005) Improvement of motor function with noninvasive cortical stimulation in a patient with chronic stroke. Neurorehabil Neural Repair 19:14-19. doi:10.1177/ 1545968304272698

57. Iadecola C (1997) Bright and dark sides of nitric oxide in ischemic brain injury. Trends Neurosci 20:132-139. doi:10.1016/ S0166-2236(96)10074-6

58. Imai F, Suzuki H, Oda J et al (2006)Neuroprotective effect of exogenous microglia in global brain ischemia. J Cereb Blood Flow Metab

59. Iosif RE, Ahlenius H, Ekdahl CT et al (2008) Suppression of stroke-induced progenitor proliferation in adult subventricular zone by tumor necrosis factor receptor 1 . J Cereb Blood Flow Metab 28:1574-1587. doi:10.1038/jcbfm.2008.47

60. Iosif RE, Ekdahl CT, Ahlenius H et al (2006) Tumor necrosis factor receptor 1 is a negative regulator of progenitor proliferation in adult hippocampal neurogenesis. J Neurosci 26:97039712. doi:10.1523/JNEUROSCI.2723-06.2006

61. Jin K, Sun Y, Xie L et al (2003) Directed migration of neuronal precursors into the ischemic cerebral cortex and striatum. Mol Cell Neurosci 24:171-189. doi:10.1016/S1044-7431(03)00159-3

62. Jin K, Xie L, Childs J et al (2003) Cerebral neurogenesis is induced by intranasal administration of growth factors. Ann Neurol 53:405-409. doi:10.1002/ana.10506

63. Johansson BB (2000) Brain plasticity and stroke rehabilitation. The Willis lecture. Stroke 31:223-230

64. Johansson BB (2004) Brain plasticity in health and disease. Keio J Med 53:231-246. doi:10.2302/kjm.53.231

65. Kalluri HS, Vemuganti R, Dempsey RJ (2007) Mechanism of insulin-like growth factor I-mediated proliferation of adult neural progenitor cells: role of Akt. Eur J Neurosci 25:1041-1048. doi:10.1111/j.1460-9568.2007.05336.x

66. Karhunen H, Virtanen T, Schallert T, Sivenius J, Jolkkonen J (2003) Forelimb use after focal cerebral ischemia in rats treated with an alpha 2-adrenoceptor antagonist. Pharmacol Biochem Behav 74:663-669. doi:10.1016/S0091-3057(02)01053-5

67. Katsuki H, Nakai S, Hirai Y et al (1990) Interleukin-1 beta inhibits long-term potentiation in the CA3 region of mouse hippocampal slices. Eur J Pharmacol 181:323-326. doi:10.1016/00142999(90)90099-R

68. Keller AF, Gravel M, Kriz J (2008) Live imaging of amyotrophic lateral sclerosis pathogenesis: disease onset is characterized by marked induction of GFAP in Schwann cells. Glia. doi:10.1002/ glia.20836

69. Kelly S, Bliss TM, Shah AK et al (2004) Transplanted human fetal neural stem cells survive, migrate, and differentiate in ischemic rat cerebral cortex. Proc Natl Acad Sci USA 101:1183911844. doi:10.1073/pnas.0404474101

70. Kitamura $Y$, Takata K, Inden M et al (2004) Intracerebroventricular injection of microglia protects against focal brain ischemia. J Pharmacol Sci 94:203-206. doi:10.1254/jphs.94.203

71. Kitamura Y, Yanagisawa D, Inden M et al (2005) Recovery of focal brain ischemia-induced behavioral dysfunction by intracerebroventricular injection of microglia. J Pharmacol Sci 97:289293. doi:10.1254/jphs.SC0040129

72. Kleinfeld D, Mitra PP, Helmchen F, Denk W (1998) Fluctuations and stimulus-induced changes in blood flow observed in individual capillaries in layers 2 through 4 of rat neocortex. Proc Natl Acad Sci USA 95:15741-15746. doi:10.1073/pnas.95. 26.15741

73. Kokaia Z, Lindvall O (2003) Neurogenesis after ischaemic brain insults. Curr Opin Neurobiol 13:127-132. doi:10.1016/S09594388(03)00017-5

74. Kristian T, Gido G, Kuroda S, Schutz A, Siesjo BK (1998) Calcium metabolism of focal and penumbral tissues in rats subjected to transient middle cerebral artery occlusion. Exp Brain Res 120:503-509. doi:10.1007/s002210050424

75. Kriz J (2006) Inflammation in ischemic brain injury: timing is important. Crit Rev Neurobiol 18:145-157

76. Kriz J, Beaulieu JM, Julien JP, Krnjevic K (2005) Up-regulation of peripherin is associated with alterations in synaptic plasticity in CA1 and CA3 regions of hippocampus. Neurobiol Dis 18:409420. doi:10.1016/j.nbd.2004.10.009

77. Ladeby R, Wirenfeldt M, Garcia-Ovejero D et al (2005) Microglial cell population dynamics in the injured adult central nervous system. Brain Res Brain Res Rev 48:196-206. doi:10.1016/ j.brainresrev.2004.12.009

78. Lai AY, Todd KG (2008) Differential regulation of trophic and proinflammatory microglial effectors is dependent on severity of neuronal injury. Glia 56:259-270. doi:10.1002/glia.20610

79. Lalancette-Hebert M, Gowing G, Simard A, Weng YC, Kriz J (2007) Selective ablation of proliferating microglial cells exacerbates ischemic injury in the brain. J Neurosci 27:2596-2605. doi:10.1523/JNEUROSCI.5360-06.2007

80. Lalancette-Hebert M, Phaneuf D, Soucy G, Weng YC, Kriz J (2009) Live imaging of Toll-like receptor 2 response in cerebral ischaemia reveals a role of olfactory bulb microglia as modulators of inflammation. Brain. doi:10.1093/brain/awn345

81. Lecomte MJ, Basseville M, Landon F, Karpov V, Fauquet M (1998) Transcriptional activation of the mouse peripherin gene by leukemia inhibitory factor: involvement of STAT proteins. J Neurochem 70:971-982

82. Lee RG, van Donkelaar P (1995) Mechanisms underlying functional recovery following stroke. Can J Neurol Sci 22:257-263

83. Lehnardt S, Lehmann S, Kaul D et al (2007) Toll-like receptor 2 mediates CNS injury in focal cerebral ischemia. J Neuroimmunol 190:28-33. doi:10.1016/j.jneuroim.2007.07.023

84. Li Y, Jiang N, Powers C, Chopp M (1998) Neuronal damage and plasticity identified by microtubule-associated protein 2 , growthassociated protein 43 , and cyclin D1 immunoreactivity after focal cerebral ischemia in rats. Stroke 29:1972-1980 discussion 1980 1971

85. Liu Z, Fan Y, Won SJ et al (2007) Chronic treatment with minocycline preserves adult new neurons and reduces functional impairment after focal cerebral ischemia. Stroke 38:146-152. doi:10.1161/01.STR.0000251791.64910.cd

86. Lledo PM, Alonso M, Grubb MS (2006) Adult neurogenesis and functional plasticity in neuronal circuits. Nat Rev Neurosci 7:179-193. doi:10.1038/nrn1867

87. Lo EH, Dalkara T, Moskowitz MA (2003) Mechanisms, challenges and opportunities in stroke. Nat Rev Neurosci 4:399-415. doi:10.1038/nrn1106

88. Loddick SA, Rothwell NJ (1996) Neuroprotective effects of human recombinant interleukin-1 receptor antagonist in focal cerebral ischaemia in the rat. J Cereb Blood Flow Metab 16:932940. doi:10.1097/00004647-199609000-00017

89. Maysinger D, Behrendt M, Lalancette-Hebert M, Kriz J (2007) Real-time imaging of astrocyte response to quantum dots: in vivo screening model system for biocompatibility of nanoparticles. Nano Lett 7:2513-2520

90. Mergenthaler P, Dirnagl U, Meisel A (2004) Pathophysiology of stroke: lessons from animal models. Metab Brain Dis 19:151167. doi:10.1023/B:MEBR.0000043966.46964.e6 
91. Ming GL, Song H (2005) Adult neurogenesis in the mammalian central nervous system. Annu Rev Neurosci 28:223-250. doi:10.1146/annurev.neuro.28.051804.101459

92. Misgeld T, Kerschensteiner M (2006) In vivo imaging of the diseased nervous system. Nat Rev Neurosci 7:449-463. doi:10.1038/ nrn1905

93. Miwa T, Furukawa S, Nakajima K, Furukawa Y, Kohsaka S (1997) Lipopolysaccharide enhances synthesis of brain-derived neurotrophic factor in cultured rat microglia. J Neurosci Res 50:1023-1029. doi:10.1002/(SICI)1097-4547(19971215)50:6< 1023::AID-JNR13>3.0.CO;2-5

94. Monje ML, Toda H, Palmer TD (2003) Inflammatory blockade restores adult hippocampal neurogenesis. Science 302:1760 1765. doi:10.1126/science. 1088417

95. Nakajima K, Kohsaka S (2004) Microglia: neuroprotective and neurotrophic cells in the central nervous system. Curr Drug Targets Cardiovasc Haematol Disord 4:65-84. doi:10.2174/ 1568006043481284

96. Nakamura T, Xi G, Hua Y, Hoff JT, Keep RF (2003) Nestin expression after experimental intracerebral hemorrhage. Brain Res 981:108-117. doi:10.1016/S0006-8993(03)02991-3

97. Neumann J, Gunzer M, Gutzeit HO et al (2006) Microglia provide neuroprotection after ischemia. FASEB J 20:714-716

98. Neumann J, Sauerzweig S, Ronicke R et al (2008) Microglia cells protect neurons by direct engulfment of invading neutrophil granulocytes: a new mechanism of CNS immune privilege. J Neurosci 28:5965-5975. doi:10.1523/JNEUROSCI.0060-08.2008

99. Nguyen MD, Julien JP, Rivest S (2002) Innate immunity: the missing link in neuroprotection and neurodegeneration? Nat Rev Neurosci 3:216-227. doi:10.1038/nrn752

100. Nudo RJ, Wise BM, SiFuentes F, Milliken GW (1996) Neural substrates for the effects of rehabilitative training on motor recovery after ischemic infarct. Science 272:1791-1794

101. Nygren J, Wieloch T (2005) Enriched environment enhances recovery of motor function after focal ischemia in mice, and downregulates the transcription factor NGFI-A. J Cereb Blood Flow Metab 25:1625-1633. doi:10.1038/sj.jcbfm.9600157

102. O'Donnell SL, Frederick TJ, Krady JK, Vannucci SJ, Wood TL (2002) IGF-I and microglia/macrophage proliferation in the ischemic mouse brain. Glia 39:85-97. doi:10.1002/glia.10081

103. Offner H, Subramanian S, Parker SM et al (2006) Experimental stroke induces massive, rapid activation of the peripheral immune system. J Cereb Blood Flow Metab 26:654-665. doi:10.1038/sj.jcbfm.9600217

104. Ohtaki H, Ylostalo JH, Foraker JE et al (2008) Stem/progenitor cells from bone marrow decrease neuronal death in global ischemia by modulation of inflammatory/immune responses. Proc Natl Acad Sci USA 105:14638-14643. doi:10.1073/pnas.0803670105

105. Okun E, Griffioen KJ, Lathia JD et al (2008) Toll-like receptors in neurodegeneration. Brain Res Rev

106. Osterloh A, Breloer M (2008) Heat shock proteins: linking danger and pathogen recognition. Med Microbiol Immunol (Berl) 197:1-8. doi:10.1007/s00430-007-0055-0

107. Otaegi G, Yusta-Boyo MJ, Vergano-Vera E et al (2006) Modulation of the PI 3-kinase-Akt signalling pathway by IGF-I and PTEN regulates the differentiation of neural stem/precursor cells. J Cell Sci 119:2739-2748. doi:10.1242/jcs.03012

108. Pan YA, Misgeld T, Lichtman JW, Sanes JR (2003) Effects of neurotoxic and neuroprotective agents on peripheral nerve regeneration assayed by time-lapse imaging in vivo. J Neurosci 23:11479-11488

109. Parysek LM, Goldman RD (1988) Distribution of a novel $57 \mathrm{kDa}$ intermediate filament (IF) protein in the nervous system. J Neurosci 8:555-563

110. Patel PM, Drummond JC, Sano T et al (1993) Effect of ibuprofen on regional eicosanoid production and neuronal injury after fore- brain ischemia in rats. Brain Res 614:315-324. doi:10.1016/ 0006-8993(93)91050-3

111. Pluchino S, Martino G (2008) Neural stem cell-mediated immunomodulation: repairing the haemorrhagic brain. Brain 131:604 605. doi:10.1093/brain/awn015

112. Portier MM, Escurat M, Landon F, Djabali K, Bousquet O (1993) Peripherin and neurofilaments: expression and role during neural development. C R Acad Sci III 316:1124-1140

113. Raivich G, Jones LL, Werner A et al (1999) Molecular signals for glial activation: pro- and anti-inflammatory cytokines in the injured brain. Acta Neurochir Suppl (Wien) 73:21-30

114. Relton JK, Martin D, Thompson RC, Russell DA (1996) Peripheral administration of interleukin-1 receptor antagonist inhibits brain damage after focal cerebral ischemia in the rat. Exp Neurol 138:206-213. doi:10.1006/exnr.1996.0059

115. Rhrich-Haddout F, Klosen P, Portier MM, Horvat JC (1997) Expression of peripherin, NADPH-diaphorase and NOS in the adult rat neocortex. Neuroreport 8:3313-3316. doi:10.1097/ 00001756-199710200-00024

116. Rogove AD, Lu W, Tsirka SE (2002) Microglial activation and recruitment, but not proliferation, suffice to mediate neurodegeneration. Cell Death Differ 9:801-806. doi:10.1038/sj.cdd. 4401041

117. Rolls A, Shechter R, London A et al (2007) Toll-like receptors modulate adult hippocampal neurogenesis. Nat Cell Biol 9:10811088. doi:10.1038/ncb1629

118. Ropper AH a B, R.H. 2005 Adams and Victor's Principles of neurology. New York

119. Rothwell NJ, Hopkins SJ (1995) Cytokines and the nervous system II: actions and mechanisms of action. Trends Neurosci 18:130-136. doi:10.1016/0166-2236(95)93890-A

120. Sasaki T, Kitagawa K, Sugiura $S$ et al (2003) Implication of cyclooxygenase- 2 on enhanced proliferation of neural progenitor cells in the adult mouse hippocampus after ischemia. J Neurosci Res 72:461-471. doi:10.1002/jnr.10595

121. Sasaki T, Kitagawa K, Yamagata K et al (2004) Amelioration of hippocampal neuronal damage after transient forebrain ischemia in cyclooxygenase-2-deficient mice. J Cereb Blood Flow Metab 24:107-113. doi:10.1097/01.WCB.0000100065.36077.4A

122. Schabitz WR, Kollmar R, Schwaninger M et al (2003) Neuroprotective effect of granulocyte colony-stimulating factor after focal cerebral ischemia. Stroke 34:745-751. doi:10.1161/01.STR. 0000057814.70180.17

123. Schaffer CB, Friedman B, Nishimura N et al (2006) Two-photon imaging of cortical surface microvessels reveals a robust redistribution in blood flow after vascular occlusion. PLoS Biol 4:e22. doi:10.1371/journal.pbio.0040022

124. Scherbel U, Raghupathi R, Nakamura M et al (1999) Differential acute and chronic responses of tumor necrosis factor-deficient mice to experimental brain injury. Proc Natl Acad Sci USA 96:8721-8726. doi:10.1073/pnas.96.15.8721

125. Schwartz M (2003) Macrophages and microglia in central nervous system injury: are they helpful or harmful? J Cereb Blood Flow Metab 23:385-394. doi:10.1097/00004647-200304000-00001

126. Seil FJ (1997) Recovery and repair issues after stroke from the scientific perspective. Curr Opin Neurol 10:49-51

127. Six I, Gasan G, Mura E, Bordet R (2003) Beneficial effect of pharmacological mobilization of bone marrow in experimental cerebral ischemia. Eur J Pharmacol 458:327-328. doi:10.1016/ S0014-2999(02)02785-1

128. Stahel PF, Shohami E, Younis FM et al (2000) Experimental closed head injury: analysis of neurological outcome, bloodbrain barrier dysfunction, intracranial neutrophil infiltration, and neuronal cell death in mice deficient in genes for pro-inflammatory cytokines. J Cereb Blood Flow Metab 20:369-380. doi:10.1097/00004647-200002000-00019 
129. Steinberg BA, Augustine JR (1997) Behavioral, anatomical, and physiological aspects of recovery of motor function following stroke. Brain Res Brain Res Rev 25:125-132. doi:10.1016/ S0165-0173(97)00013-1

130. Stellwagen D, Malenka RC (2006) Synaptic scaling mediated by glial TNF-alpha. Nature 440:1054-1059. doi:10.1038/ nature 04671

131. Sterneck E, Kaplan DR, Johnson PF (1996) Interleukin-6 induces expression of peripherin and cooperates with Trk receptor signaling to promote neuronal differentiation in PC12 cells. J Neurochem 67:1365-1374

132. Sugimoto K, Iadecola C (2003) Delayed effect of administration of COX-2 inhibitor in mice with acute cerebral ischemia. Brain Res 960:273-276. doi:10.1016/S0006-8993(02)03805-2

133. Tonchev AB, Boneva NB, Kaplamadzhiev DB et al (2008) Expression of neurotrophin receptors by proliferating glia in postischemic hippocampal CA1 sector of adult monkeys. J Neuroimmunol 205(1-2):20-24

134. Vila N, Reverter JC, Yague J, Chamorro A (2000) Interaction between interleukin- 6 and the natural anticoagulant system in acute stroke. J Interferon Cytokine Res 20:325-329. doi:10.1089/ 107999000312478

135. Vilcek J, Feldmann M (2004) Historical review: cytokines as therapeutics and targets of therapeutics. Trends Pharmacol Sci 25:201-209. doi:10.1016/j.tips.2004.02.011

136. Wakselman S, Bechade C, Roumier A et al (2008) Developmental neuronal death in hippocampus requires the microglial CD11b integrin and DAP12 immunoreceptor. J Neurosci 28:8138-8143. doi:10.1523/JNEUROSCI.1006-08.2008

137. Weng YC, Kriz J (2007) Differential neuroprotective effects of a minocycline-based drug cocktail in transient and permanent focal cerebral ischemia. Exp Neurol

138. Wieloch T, Nikolich K (2006) Mechanisms of neural plasticity following brain injury. Curr Opin Neurobiol 16:258-264. doi:10.1016/j.conb.2006.05.011
139. Winship IR, Murphy TH (2008) In vivo calcium imaging reveals functional rewiring of single somatosensory neurons after stroke. J Neurosci 28:6592-6606. doi:10.1523/JNEUROSCI.062208.2008

140. Witte OW (2000) Physiological basis of pathophysiological brain rhythms. Acta Neurobiol Exp (Warsz) 60:289-297

141. Yamasaki Y, Matsuura N, Shozuhara H et al (1995) Interleukin1 as a pathogenetic mediator of ischemic brain damage in rats. Stroke 26:676-680 discussion 681

142. Yrjanheikki J, Keinanen R, Pellikka M, Hokfelt T, Koistinaho J (1998) Tetracyclines inhibit microglial activation and are neuroprotective in global brain ischemia. Proc Natl Acad Sci USA 95:15769-15774. doi:10.1073/pnas.95.26.15769

143. Yrjanheikki J, Tikka T, Keinanen R et al (1999) A tetracycline derivative, minocycline, reduces inflammation and protects against focal cerebral ischemia with a wide therapeutic window. Proc Natl Acad Sci USA 96:13496-13500. doi:10.1073/ pnas.96.23.13496

144. Zhao BQ, Wang S, Kim HY et al (2006) Role of matrix metalloproteinases in delayed cortical responses after stroke. Nat Med 12:441-445. doi:10.1038/nm1387

145. Zhu C, Liu Z, Gui L et al (2008) Mutated IkappaBalpha represses proliferation of immortalized neural progenitor cells and prevents their apoptosis after oxygen-glucose deprivation. Brain Res 1244:24-31

146. Zhu L, Ramboz S, Hewitt D et al (2004) Non-invasive imaging of GFAP expression after neuronal damage in mice. Neurosci Lett 367:210-212. doi:10.1016/j.neulet.2004.06.020

147. Ziegler G, Harhausen D, Schepers C et al (2007) TLR2 has a detrimental role in mouse transient focal cerebral ischemia. Biochem Biophys Res Commun 359:574-579. doi:10.1016/ j.bbrc.2007.05.157 